\title{
A REVIEW TO ASSESS OPPORTUNITIES AND SECURITY RISK CHALLENGES IN CLOUD COMPUTING
}

\author{
Shikha Gupta ${ }^{1}$, Anil K Saini \\ ${ }^{1}$ College of Computing Sciences and Information Technology (CCSIT), TMU, Moradabad, India \\ ${ }^{2}$ University School of Management Studies, GGS Indraprasth University, Delhi, India
}

\begin{abstract}
In today's competitive world, organizations are under increasing pressure to develop efficiently and convert their IT practices to achieve more with less. Cloud Computing is a flexible technology that can support a wide variety of application. In contrast to grid computing and clustering, cloud computing is service oriented, loosely coupled, TCP/IP based Business Model technology that provides high security and advantage of virtualization and strong fault tolerance. The purpose of the paper is to provide a review of the cloud computing concepts and challenges facing organizations in its adoption
\end{abstract}

Keywords-Cloud Computing, flexible technology, Business Model technology, virtualization

\section{INTRODUCTION}

In today's competitive world, organizations are under increasing pressure to develop efficiently and convert their IT practices to achieve more with less. Business needs to have reduced time-to-market, better agility, higher availability, and reduced expenditures to meet the changing business requirements. In this, cloud computing has proved to be an infrastructure that helps in getting rid of expensive computing hardware. The term "cloud" refers to Internet or communication system that deals with the users having different needs with the same set of physical resources. Cloud Computing is a flexible technology that can support a wide variety of application. In contrast to grid computing and clustering, cloud computing is service oriented, loosely coupled, TCP/IP based Business Model technology that provides high security and advantage of virtualization and strong fault tolerance.

\section{EVOLUTION OF CLOUD COMPUTING}

As per EMC Corporation and IBM, "Cloud Computing is a model for enabling ubiquitous, convenient, on-demand network access to a shared pool of configurable computing resources (e.g., networks, servers, storage, applications, and services) that can be rapidly provisioned and released with minimal management effort or service provider interaction."

As per Wikipedia, "Cloud computing is the delivery of services of the computing a service rather than a product, whereby shared resources, software, and information are provided to computers and other devices as a utility (like the electricity grid) over a network (typically the Internet)."

As per [1], cloud computing is a collection of IT resources (servers, databases and applications) which are available on an on-demand basis, provided by a service company, available through the internet and provide resource pooling among multiple users.
Cloud Computing is an evolution of the widespread acceptance of virtualization, service-oriented architecture, automatic, and utility computing[2][3]. The actual term "cloud" is borrowed from telecommunications companies, who until the 1990s offered primarily dedicated point to point data circuits, began offering Virtual Private Network (VPN) services with similar quality of service but at much lower cost. In initial stages, "cloud" was used to represent the computing gap between the provider and the end user. In 1997, Professor Ramnath Chellapa of Emory University and the University of South California referred cloud computing as "computing paradigm where the boundaries of computing will be determined by economic rationale rather than technical limits alone.'In October 2007, IBM and Google announced partnership in cloud computing. This makes "cloud computing" popular. Besides these, the Amazon Elastic Compute Cloud (EC2), Google App Engine and Microsoft's Windows Azure also represented a promising theoretical foundation of cloud services. The cloud computing is divided into five layers including clients, applications, platform, infrastructure and servers (Fig.1)

\begin{tabular}{|c|}
\hline Client \\
\hline Application \\
\hline Platform \\
\hline Infrastructure \\
\hline Servers \\
\hline
\end{tabular}

Fig 1 Layering architecture of Cloud Computing 


\section{BASIC TERMINOLOGY OF CLOUD} COMPUTING

The basic cloud concept has brought a list of terminology with it $[1][7][8][9]$.

Virtualization: It is a technique that extracts the physical characteristics of IT resources from resource users. It enables users create virtual resources from the pool of resources. Virtualization provides better flexibility from stipulation of IT resources compared to stipulation in a nonvirtualized environment. It helps optimize resource utilization and delivering resources more efficiently.

Cloud: The term Cloud refers to a Network or Internet or any communication system. In other words, Cloud is some technology, which is there at remote location. Cloud provides services over network such as on public networks or on private networks, i.e., WAN, LAN or VPN.

IT resources: An IT resource is a physical or virtual ITrelated object that can be either software based, such as a virtual server, or hardware-based, such as a physical server. Service: It refers to a set of related software functionalities that can be used together with the policies that control its usage.

Scaling: Scaling represents the ability of the IT resource to handle increase or decrease in usage of demands. There are two types of scaling: Horizontal Scaling (scaling in and scaling out) and Vertical Scaling (scaling up and scaling down).

Cloud services: A cloud service is an IT resource that can be accessed remotely via a cloud. A cloud service can exist as a simple Web-based software program with a technical interface invoked via the use of a messaging protocol, or as a remote access point for administrative tools or larger environments.

\section{CLOUD COMPUTING CHARACTERSTICS}

Researchers have stated various characteristics of cloud computing. As per [2][4][5][6], these characteristics are as follows :

1. On-demand self-service: A consumer can independently stipulate computing capabilities as needed automatically without requiring human interaction with each service's provider.

2. Broad network access: Capabilities are available over the network and accessed through standard mechanisms that promote use by different types of client platforms

3. Resource pooling: The provider's computing resources are pooled to serve multiple consumers using a multi-tenant model, with different physical and virtual resources dynamically assigned to consumer according to their demand.

4. Rapid elasticity: Capabilities can be rapidly and flexibly provisioned to quickly scale out and rapidly released to quickly scale in. To the consumer, the capabilities available at any time to purchase.

5. Measured Service: Cloud systems automatically control and optimize resource use by influencing a metering capability at some level of abstraction of the services provided. Resource usage can be monitored, controlled, and reported which provides transparency to both the provider and consumer of the utilized service.

\section{CLOUD COMPUTING SERVICES}

1. Software as a Service (SaaS): In this, the capability which is provided to the consumer is to use the provider's applications running on a cloud. The applications are accessible from various clients through a thin client interface such as a web browser. The consumer does not manage or control the network, servers, operating systems, storage, or individual application capabilities, with the possible exemption of limited user-specific application configuration settings [2].

2. Platform as a Service (PaaS): In this, the capability which is provided to the consumer is to install onto the cloud infrastructure or acquired applications using programming languages and supported tools. The consumer does not manage or control the network, servers, operating systems, or storage, but has control over the installed applications and possibly application hosting environment configurations [4].

3. Infrastructure as a Service (IaaS): In this, the capability which is provided to the consumer is to stipulate processing, storage, networks, and other fundamental computing resources where the consumer is able to install and run random software, which can include operating systems and applications. The consumer has control only over operating systems, storage, installed applications, and possibly limited control of select networking components[2][4].

There are more than one vendor who provide cloud computing services. Some of them are Google, Salesforce, Microsoft, Amazon, Zoho, Yahoo and Rackspace.

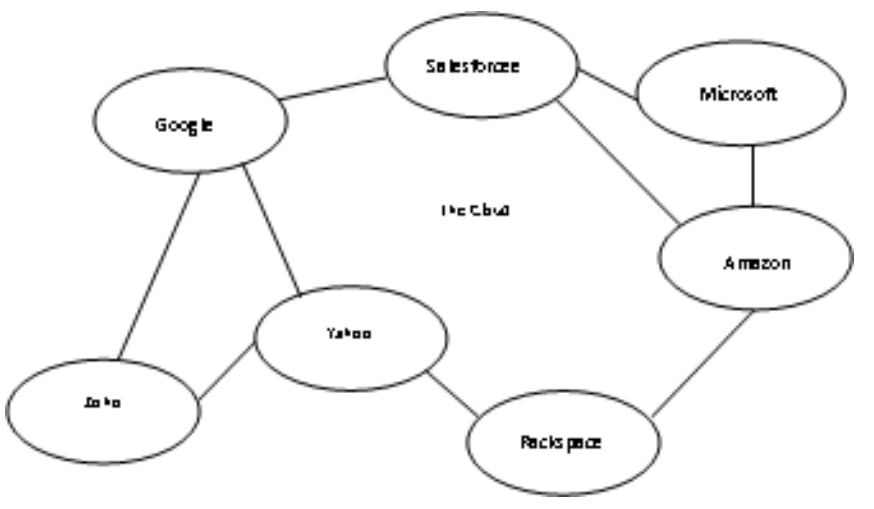


Different vendors provide different type of services dealing in different cloud models. Some of them are listed below:

\begin{tabular}{|l|l|l|}
\hline Provider Name & $\begin{array}{l}\text { Service } \\
\text { Model }\end{array}$ & $\begin{array}{l}\text { Deployment } \\
\text { Model }\end{array}$ \\
\hline Ninefold & PaaS & Public \\
\hline LunaCloud & IaaS & Public, Private \\
\hline $\begin{array}{l}\text { Amazon Web } \\
\text { Services }\end{array}$ & IaaS & Public \\
\hline Windows Azure & IaaS, PaaS & Public \\
\hline $\begin{array}{l}\text { Google } \\
\text { Compute } \\
\text { Engine }\end{array}$ & IaaS & Public \\
\hline GoGrid & IaaS & Public, Private \\
\hline Joyent & IaaS & Private \\
\hline AppHarbor & PaaS & Public \\
\hline Rackspace & IaaS & $\begin{array}{l}\text { Public, Private, } \\
\text { Hybrid }\end{array}$ \\
\hline EngineYard & PaaS & Public \\
\hline $\begin{array}{l}\text { SalesForge1 } \\
\text { Platform }\end{array}$ & PaaS & Public \\
\hline Clever Cloud & PaaS & Public \\
\hline IBM Cloud & IaaS & Private, Hybrid \\
\hline
\end{tabular}

\section{CLOUD COMPUTING RISKS AND}

\section{CHALLENGES}

Cloud computing offers many advantages such as cost reduction, better service quality, increased business flexibility and anytime, anywhere services. But one the other hand, many of the issues are also associated with it. Cloud computing may create a reliance on the provider and may make it difficult to move to another platform. Also, there is always a risk that the cloud provider may change business models or even go out of the business. It is possible that cloud service provider who stores and manages data may not have adequate security measures. Then our data is at high security alert. Also, the providers can access the client data which could be a major risk. There is multilevel risk associated with cloud computing which is another challenge for it.

Interrupted availability of services at provider's/user's end, the limited elasticity, lack of monitoring solutions and data lock-in bottleneck in transition from one service provider to other due to lack of standards is also a major issue in cloud computing. From business perspective, the problem of one client can affect the working of another client. Regulations and laws of provider country also matters a lot.

Cloud is vulnerable to viruses, worms, hackers and cyber attacks increasing theft to private information. Google has also encountered an attack from China. The physical location of storage is one the major risk domain. Also, the organization is unaware or clueless about physical access to storage or visibility to storage and backup processes. Google Gmail went down for two hours because of this.
Service Level Agreement can be one solution to these problems. It covers all the aspects of IT Service Management. This includes all the processes that allow planning, organizing, directing, and controlling the provisioning of IT services for the purpose of service availability, performance, accuracy, capacity and security.

Therefore, before adapting to cloud computing, one should keep in mind the below seven security concerns:

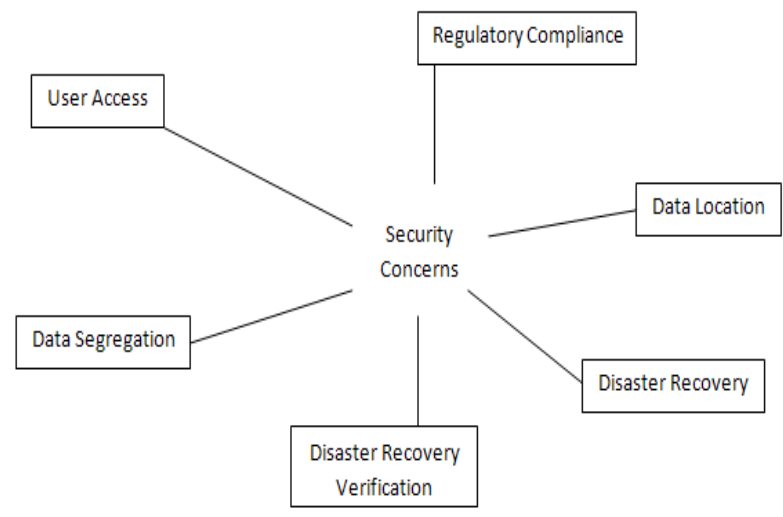

As per [10] factors like Competitive advantage, Better interconnectivity, Low start-up costs, Reduced risk associated with that cost in case of failure, less risks of purchasing servers, data-centres because of pay-as-you-go feature of cloud computing, Flexibility towards changes in demand, Security of scale contribute positively towards cloud computing decisions, there are lot of factors which contribute negatively towards this decision which are as follows

- $\quad$ Performance unpredictability risk

- Business risks fate-sharing, problem of one client affecting other

- Legal risks like providers' liability to protect data on cloud, regulations and laws of provider country

- Policy and original risk like risks related to compliance, insufficient expertise in Service Level Agreement, Provider's business failure, Service termination, Acquisition of cloud provider, Supply chain failure if provider outsources few services

- Insider risks

- Transit risk as data will be in transit more often between users and cloud and between several physical servers within the cloud

- $\quad$ Security risks like inadequate security measures taken by Cloud service provider, risk of cyber attackers such as organized criminals, hackers, terrorists and intruders it being repository of many clients so has "high value", Authentication and Authorization, Phishing, Virtual Machine attacks, Network attacks, Forensics implications. Technical Issues like interrupted availability of services at provider's/user's end such as bugs on provider's machine service bottlenecks etc or data lock-in bottleneck in transition from one service provider to other due to lack of standards[10][11] 


\section{SUGGESTIVE STRATEGIES FOR} ADDRESSING RISKS[11]

There is need to deal with risks that an enterprise might recognize with in an effective manner with proper planning flexible enough to deal with continuously evolving information risks. The risk management program should deal with risk without hampering the privacy of enterprise customers. Properly drafted service level agreement (SLA) play an important role in curbing security problems to a large extant by taking note of few important issues like enlisting the complete information assets of the organization, proper and correct cataloguing of organization's data , data encryption before being transferred or transiting or stored from one location to the other. Any and all additional controls for information that is sensitive or of high value to the organization should be clearly defined in the agreement.

\section{CONCLUSION}

The paper identifies cloud computing concepts ranging from the basic definition to history and evolution. The paper also identifies the characteristics and services provided through the technology.

The paper lists various vendors in these fields to make the organizations understand the services provided by different vendors. Though the cloud computing brings with it lots of secured services and facilities it also has lot of challenges which need to be addressed while adopting the technology

\section{ACKNOWLEDGEMENTS}

The author would like to acknowledge the effort of Ms. Sonali Chawla and Mr. Bhishm Yadav in contributing towards the paper

\section{REFERENCES}

[1] "A Study on Cloud Computing Security Challenges" by Santosh Bulusu and Kalyan Sudia, School of Computing at Blekinge Institute of Technology

[2] "Cloud Computing Basics" by J. Srinivas, K. Venkata Subba Reddy and Dr. A. Moiz Qyster, Published by International Journal of Advanced Research in Computer and Communication Engineering Vol. 1, Issu 5, July 2012

[3] "Information Storage and Management: Storing, Managing and Protecting Digital Information" by G. Somasundaram, Alok Shrivastava

[4] "The Characteristics of Cloud Computing" by Chunye Gong, Jie Liu, Qiang Zhang, Haitao Chen and Zhenghu Gong, 39th International Conference on Parallel Processing Workshop, 2010

[5] "The NIST Definition of Cloud Computing" by Peter Mell and Timothy Grance, National Institute of Standards and Technology(NIST), Special Publication 800-145
[6] 5 cloud computing advantages (and 5 potential problems) by Taneja Group published on 09/16/14

[7] http://cloudschool.com/system/application/images/ Cloud_Module1_online.pdf

[8] http://cloudschool.com/system/application/images/ Cloud_Module2_online.pdf

[9] http://whatiscloud.com/basic_concepts_and_termin ology/on_premise

[10] "Adoption of Cloud Computing in Organizations", Hasan Nuseibeh University of South Florida, hnuseibeh@usf.edu, Association for Information Systems AIS Electronic Library (AISeL)

[11] "An Overview of Cloud Computing Challenges and Its Security Concerns", Krishnun Sansurooah, Edith Cowan University, Edith Cowan University Research Online ECU Publications 2012. 